\title{
ENCONTROS ALEGRES NO CIBERESPAÇO: DISCURSOS SOBRE AMBIENTES E OBJETOS DE APRENDIZAGEM
}

\author{
AURECI DE FATIMA DA COSTA ${ }^{1}$ \\ Universidade do Vale do Sapucaí \\ Faculdade de Filosofia, Ciências e Letras Eugênio Pacelli \\ Av. Pref. Tuany Toledo, 470 - 37550-000 - Pouso Alegre - MG - Brasil
}

aureci.costa.a@gmail.com

\begin{abstract}
Resumo. O presente estudo visa, a partir da perspectiva da Análise de Discurso, compreender um dos modos de produção e circulação do conhecimento em nossa sociedade, elegendo para análise os ambientes e objetos de aprendizagem (OAs). Interessa-nos investigar como os sentidos de ambientes e objetos de aprendizagem se constituem na materialidade significante virtual (digital), considerando a história e a ideologia (PECHEUX, 1995) como constitutivas desse processo. Busca-se investigar como se produz a construção histórica e imaginária desse objeto na denominada "sociedade da informação", formulada como resultado da globalização e do crescente avanço das tecnologias. Neste acontecimento, entendemos que o conhecimento está ligado basicamente à tecnologia (ORLANDI, 2017) produzindo o efeito da valorização do capital conhecimento.
\end{abstract}

Palavras-chave: discurso; ambientes e objetos de aprendizagem; tecnologias; imaginário.

\begin{abstract}
The present study aims, from the perspective of Discourse Analysis, to understand one of the modes of production and circulation of knowledge in our society, choosing for analysis the environments and objects of learning $(O A s)$. We are interested in investigating how the meanings of environments and learning objects are constituted in the virtual (digital) significant materiality, considering history and ideology (PECCHEUX, 1995) as constitutive of this process. This analysis seeks to understand the historical and imaginary construction of this object in the so-called "information society", formulated as a result of globalization and the growing advance of technologies. In this event, we understand that knowledge is basically linked to technology (ORLANDI, 2017) producing the effect of valuing knowledge capital.
\end{abstract}

Keywords: discourse; learning environments; learning objects; technologies; imaginary.

\footnotetext{
${ }^{1}$ Doutora em Linguística pela Uniamp. Realizou, entre 2016 e 2017, Estágio Pós-doutoral no Programa de Pós-graduação em Ciências da Linguagem da UNIVÁS (Bolsista PNPD/CAPES).
} 


\section{INTRODUÇÃO}

O trabalho aqui apresentado é desenvolvido em perspectiva histórico-discursiva. Consoante ao pensamento de Orlandi (1994, p. 53) de que sem história não há sentido e de que não podemos falar em sociedade sem relacioná-la com a história, é que trago à análise um objeto constituído para o processo de ensino/aprendizagem digital. No caso, em questão, aquele que no discurso dominante é dito objeto de aprendizagem.

Objeto que circula com outras denominações: objeto educacional, objeto de ensino, objeto virtual de aprendizagem, mas que, na maioria das vezes, é significado numa mesma direção de sentidos, silenciando a historicidade, o jogo de constituição do conhecimento, comumente apagado quando se trata de tecnologias digitais e sua organização em rede. Objeto constituído por uma pluralidade de vozes que ressoam memórias da globalização, da inserção das TICs na sociedade, da sociedade da informação que elabora, entre outros discursos, o da aprendizagem continuada, do aprender a aprender, do saber compartilhado (sociedade em rede), o que levaria, no entendimento de Lévy (1999) à potencialização da cibercultura.

O que temos, na realidade, conforme Dias \& Couto (2011) é um processo histórico e político mais amplo, que não se inicia com a popularização da Internet, mas com a globalização - implantação das redes mundiais de informação e comunicação. Segundo as autoras, "a popularização da internet, no entanto, é parte desse processo. E nele as redes sociais assumem papel preponderante no que diz respeito à divulgação do conhecimento e aos modos de subjetivação e individuação do sujeito" (DIAS; COUTO, 2011, p. 633).

Compreendido assim, as tecnologias não devem ser consideradas independentes de uma teoria ou como mera aplicação desta, pois longe de serem apenas questões técnicas, são também questões teóricas, ao estarem vinculadas a aspectos econômicos, sociais, culturais (PÊCHEUX, apud HENRY, Paul, 1993) e cada diferente tecnologia gera necessariamente uma mudança na cultura e na memória, visto que, cada cultura digital traz em si uma memória. Tendo em vista o viés que estamos analisando, compreendemos que não são apenas os instrumentos (tecnologias) que mudam, mas a relação do sujeito com o conhecimento. Conforme Orlandi (2003), "com as novas tecnologias de linguagem há uma reorganização do trabalho intelectual" (ORLANDI, 2003, p. 80). É sobre essa reorganização que investimos nossa análise.

Disponível desde a década de 80, o computador, ligado à internet, tem sido usado largamente para fins educativos. A atividade educacional ocorrida através desse meio, denominada $\mathrm{EaD}$ (Educação a Distância) online tem organizado sua prática comprometida com o discurso de eficácia da tecnologia para a democratização do ensino e aumento do conhecimento. É justamente, nessa última questão que queremos nos deter, propondo-nos a pensar os equívocos que se operam na FD (formação discursiva) da sociedade da informação que significa conhecimento pela adição, pelo acúmulo. E a escola e seus sujeitos, pela falta deste. Vale lembrar que a FD discursiva se define como aquilo que a partir de uma posição dada em uma conjuntura sócio-histórica dada determina o que pode e deve se dito. Ou seja, "os sentidos não existem em si, mas são determinados pelas posições ideológicas colocadas em jogo no processo sócio-histórico em que as palavras são produzidas" (ORLANDI, 2000, p. 42), significando que as palavras mudam de sentido segundo as posições daqueles que as empregam. 
Nas últimas décadas, programas de governo têm produzido mudanças significativas nas condições de produção da formação docente e discente. Privilegia-se o aprender à distância (ensino à distância, aprendizagem à distância) atribuindo centralidade às tecnologias da informação e comunicação. Entre outras ações, há um forte investimento em pesquisa e produção de objetos digitais de aprendizagem que alocados em repositórios, dão a estes o funcionamento de uma rede, num movimento de (re)significação do sujeito e do produtor do conhecimento. O verbo aprender ganha destaque nos textos dos Organismos Internacionais (UNESCO, Banco Mundial) e nos textos das políticas públicas, ao passo que ensinar tem seus sentidos questionados.

Colocando em discussão a sociedade da informação, que desliza metaforicamente para a sociedade do conhecimento e para a sociedade do aprendizado (ou sociedade aprendente) esses textos colocam em circulação denominações tais como autoaprendizagem, autonomia e interatividade, legitimando o ciberespaço como um lugar privilegiado para renovação da educação. É na ideia de flexibilização, desierarquização que se articulam essas mudanças, principalmente em relação às estratégias pedagógicas a serem adotadas e à relação professor-aluno.

Nesse sentido, nos discursos sobre as TICs defende-se que os recursos oferecidos por elas devam ser usados a fim de facilitar e melhorar o processo de ensinoaprendizagem. Efeito de sentido de uma falha no sistema educacional. Daí, serem os objetos de aprendizagem apresentados como "instrumentos para uma nova forma de educar, facilitando a disponibilidade e acessibilidade da informação no ciberespaço" (SCHWARZELMÜLLER; ORNELLAS, s.d., p. 2). Ou mesmo, suprir a falta de recursos oferecidos nas escolas, considerando os avanços tecnológicos.

Descrito por Wiley (2001) como sendo qualquer recurso digital que possa ser utilizado para suporte ao ensino ou como qualquer entidade, digital ou não digital, que pode ser usada, reusada ou referenciada durante o aprendizado apoiado pela tecnologia, os OAs trazem sentidos outros ao campo educacional. Sentidos que podem se mover para o caminho de um modelo de ensino/aprendizagem deslocado para a condição de acesso a produtos dados, legitimando as propostas das Agências Internacionais de substituição tecnológica. Um direcionamento neotecnicista. Ignora-se nesse discurso, a educação como um processo interno, para a formação. Ignora-se que o acesso (quando o há) aos materiais prontos, não implica, por si só, a garantia à formação social. Segundo Orlandi (2017, p. 254), "o digital, sustenta, nesse imaginário, a ideologia pragmática: as coisas a saber para o trabalho e mercado".

\section{OS OBJETOS NA SOCIEDADE DA INFORMAÇÃO}

Considerando que "a técnica interpela o indivíduo contemporâneo em sujeito na relação ciberespacial, a partir de uma norma identificadora (PÊCHEUX, 1995), ou seja, a partir do funcionamento da ideologia" (DIAS, 2004, p. 49), faz-se mister observar de que maneira isso ocorre, sob imperativo tecnológico.

Já discutimos em tese de doutoramento (COSTA, 2015) que o conjunto de significações que tem sustentado as políticas de formação de professores e alunos têm seu mote na reforma estrutural pela qual a sociedade estaria passando, propiciada pela globalização e pela presença das tecnologias de comunicação e informação. Tornou-se, assim, ordinário afirmar que as mudanças ocorridas na sociedade requerem a formação 
de um novo homem que se situe neste novo espaço/acontecimento, com características determinadas pela modernidade tecnológica denominada sociedade do conhecimento. Assim, nesta sociedade, ter acesso à rede, fazer parte do ciberespaço, liga-se ao ter informação, significada conhecimento.

Para caracterizar essa mudança de paradigmas, o sociólogo espanhol Castells (2000) diz que houve uma passagem do capitalismo ao informacionalismo. Ele chama de informacional, global e em rede, a economia surgida em escala mundial nas últimas três décadas. Justifica cada uma das características da "nova economia" nos seguintes sentidos.

É informacional porque a produtividade e a competitividade de unidades ou agentes nessa economia (sejam empresas, regiões ou nações) dependem basicamente de sua capacidade de gerar, processar e aplicar de forma eficiente a informação baseada em conhecimentos. É global porque as principais atividades produtivas, o consumo e a circulação, assim como seus componentes (capital, trabalho, matériaprima, administração, informação, tecnologia e mercados) estão organizados em escala global, diretamente ou mediante uma rede de conexões entre agentes econômicos. É rede porque, nas novas condições históricas, a produtividade é gerada, e a concorrência é feita em uma rede global de interação entre redes empresariais. (CASTELLS, 2007, p. 119; grifos nossos)

É “a busca por conhecimentos e informação que caracteriza a função da produção tecnológica do informacionalismo" (CASTELLS, 2007, p. 35). Esse funcionamento mostra que a "sociedade da informação" é consequência da rede global e da capacidade de seus indivíduos de processarem a informação, gerando conhecimento. Destaque para o papel atribuído ao conhecimento como gerador de riqueza e não tanto como um bem da humanidade.

O filósofo Lévy $(2000 ; 2003)$ visualizava a possibilidade de desenvolvimento do que denominou "inteligência coletiva", "uma inteligência distribuída por toda parte, incessantemente valorizada, coordenada em tempo real que resulta em uma mobilização efetiva das competências". Segundo o autor, a coordenação dos inteligentes coletivos ocorre com a utilização das tecnologias da informação e comunicação, com base na troca de informações.

A análise de Lévy nos interessa justamente porque coloca em consideração as tecnologias como produtos da sociedade e por pensar o ciberespaço como promotor de um novo estilo de vida, a saber, o da temporalidade, da habitação de outro lugar, o nãolugar. Ao apregoar a absolvição das fronteiras do saber (não mais restrito ao espaço escolar), estabelece uma relação imaginária de que no ciberespaço há espaço para que todos aprendam, interajam, comuniquem; produzindo a ilusão da unidade, de um conhecimento a serviço de todos. Esse conhecimento que se acessa, de onde estiver, no tempo desejado, determina a construção de posições-sujeito, no que se refere à atribuição de outro lugar autorizado para o aprendizado (conhecimento) no contexto da "economia informacional global" (CASTELLS, 2000).

Nesse acontecimento, como lemos no texto acima (CASTELLS, 2007, p. 119) a "informação", no funcionamento imaginário de "acessível a todos", pois "disponível graças às tecnologias de informação e comunicação", que formaria uma "rede global de 
interação" sai de sua condição e circula produzindo seus efeitos de "conhecimento". Há a justaposição de informação e conhecimento, como se o fato de a informação circular sobre diversos e diferentes meios por si só garantisse o conhecimento.

Porém, como alerta Orlandi (2010), o sujeito que vive na sociedade da informação, necessariamente, "não conhece x", ele "sabe que x", ou seja, ele tem a ilusão de que conhece, mas o que tem é "apenas notícia/informação sobre conhecimento e não conhecimento" (ORLANDI, 2010, p. 12). É um efeito de informação, mas é representado na "sociedade do conhecimento" como autorizando o sujeito a dizer que conhece. "Ela funciona no imaginário de que saber que x é igual a saber $\mathrm{x}$, daí que saber (informar-se) é ter conhecimento e este é poder; faz parte dessa ilusão, também, pensar que desse modo há mudança social no acesso ao conhecimento e assim por diante", conclui Orlandi (p. 12). Como bem salienta Dias (2009), "a informação é a matéria-prima da construção do conhecimento, mas não é o conhecimento, portanto, não pode substituí-lo" (DIAS, 2009, p. 17).

A formação discursiva pedagógica, sustentando o imaginário sobre a sociedade da informação, assume os objetos de aprendizagem como "instrumentos para [uma] nova forma de educar, facilitando a disponibilidade e acessibilidade da informação no ciberespaço" (SCHWARZELMÜLLER; ORNELLAS, s.d., p. 2). Nessa formação, os objetos ganham protagonismo ao veicularem a ilusão da acessibilidade ao conhecimento como algo que já está lá, pronto, disponível, formatado, bastando ao sujeito a habilidade de encontrar, manipular e utilizar a informação na instantaneidade do clique. Que relações com o saber/poder isso implica? Poderíamos metaforizar dizendo que "clicar é poder". Grecco (2016) explica que

a busca pela completude é também o que propicia uma infinita busca por conteúdos acumulados em rede, por meio da ilusão do acesso, pela aparência da disposição de todo o saber ao alcance do mouse ou de um clique. Acúmulo que produz assim um efeito de completude. (GRECCO, 2016, p. 33)

Nesse imaginário (discurso pronunciado a partir de condições de produção dadas) em que o conhecimento está ligado basicamente à tecnologia, o que circula, lembra Orlandi (2017, p. 240) "é o imaginário do completo, do estabelecido, do preciso, do exato". Aí, tem, conforme a autora, a "imobilidade pelo excesso, não pela falta" O que se ignora nesse modo de aprender ou saber sobre as coisas são os modos de constituição desse conhecimento e das relações ideológicas aí investidas. E o resultado, conclui Orlandi (2017, p. 240) "é uma enorme produção de textos fundados no par informação/comunicação e que se distanciam de um projeto de conhecimento eficaz".

\section{ENCONTROS ALEGRES NO CIBERESPAÇO}

O discurso de acesso à informação torna-se retórico quando associado à inovação tecnológica, buscando produzir como efeito "encontros alegres". Tomo de empréstimo a expressão formulada por Spinoza e a trago para observar o funcionamento da discursividade sobre ambientes e objetos de aprendizagem. Spinoza acreditava que somos potencializados, ou não, dependendo como o mundo nos afeta. Conforme o autor, existem coisas no mundo que têm a capacidade de aumentar essa potência, deixando-nos animados, energizados, alegres. E que há coisas que diminuem nossa potência, tornandonos tristes. 
As recorrentes formulações que abordam as vantagens das tecnologias dos objetos de aprendizagem têm como base a concepção de que os mesmos podem tornar o aprendizado mais fácil, prazeroso, eficiente e eficaz, sendo descritos como recursos que "potencializam atividades colaborativas" (SCHWARZELMÜLLER; ORNELLAS, sd, p. 5). Ao serem apresentadas no discurso educacional com o papel "de serem instrumentos para [uma] nova forma de educar" (SCHWARZELMÜLLER; ORNELLAS, sd, p. 2) acredita-se que esses ambientes e objetos facilitariam os encontros por disponibilizarem e promoverem o acesso à informação.

Sujeito "potencializado" pela ilusão de acesso e gerenciamento do conhecimento. Acesso aos ambientes e objetos como uma forma de empoderamento. "Um sujeito que se ilude em sua onipotência e vontade, porque dá forma ao sujeito pragmático das (muitas) coisas a saber para sua satisfação" (ORLANDI, 2016, p. 69).

O sujeito, assim, pela constituição dos sentidos para ambientes e objetos de aprendizagem, via discursos do incentivo, que trazem em si um argumento desenvolvimentista, com vistas à formação de redes de colaboração, sente-se participante ativo desse processo por meio da manipulação, exposição ou produção de ambientes e objetos de aprendizagem.

Ao metaforizar a expressão "encontros alegres" de Spinoza e a analisar na relação homem/máquina, homem/objeto, no acontecimento virtual, estamos considerando que a substituição da lógica da produção pela da circulação e da comunicação traz ao jogo um sujeito na instância do imaginário, como se ali estivesse livre das coerções do mundo (DIAS, 2004): de suas exclusões, dispersões, margens e tristezas.

A circulação de discursos sobre ambientes de aprendizagem através de internet que auxiliem na construção do conhecimento por meio de "interfaces amigáveis" e de fácil uso para educandos e educadores (NOGUEIRA, 2012), e "a construção de ambientes virtuais de aprendizagem mais próximos das vontades, quereres, sentimentos e sensações dos usuários" (MACHADO, 2010), traduz ideologicamente a crença de que o ciberespaço é o ambiente ideal para a promoção de "encontros alegres". A propalada possibilidade de logar, clicar, alcançar, baixar, produzir e compartilhar conteúdos, num ambiente onde uma pessoa auxilia a outra com troca de conhecimentos, criando conhecimentos comuns, resultaria no que Lévy (1999) denominou de "inteligências coletivas" que têm por objetivo o reconhecimento e o enriquecimento mútuo das pessoas. $\mathrm{O}$ autor entende que a aprendizagem que se dá por meio de colaboração é a mais adequada à Sociedade da Informação, uma vez que o outro,

é alguém que sabe. E que sabe as coisas que eu não sei. O outro não é mais um ser assustador, ameaçador: como eu, ele ignora bastante e domina alguns conhecimentos. Mas como nossas zonas de inexperiência não se justapõem ele representa uma fonte possível de enriquecimento dos meus próprios saberes. Ele pode aumentar meu potencial de ser, e tanto mais quanto diferir de mim. (LÉVY, 1999, p. 27)

É esse encontro de "muitos para muitos" (RHEINGOLD, 1996) - simulacro da Terra Prometida, da Nova Jerusalém: reino da bondade, alegria, compatibilidade e igualdade - que interpela os indivíduos a participarem, constantemente, da produção discursiva nesse/desse espaço, pretendendo estar protegido nesta "arca de Noé" (metáfora trazida por Lévy (1999)). Acredita-se salvo da dispersão, da confusão, do "dilúvio 
informacional". Ignora que "não há nenhum fundo sólido sob o oceano das informações (LÉVY, 1999, p. 15). Ignora-se as alianças entre tecnologias, informação e mercado. Como lembra Dias (2004, p. 54), "embora haja um movimento por parte do governo, de ONGs e de outros setores da sociedade, no sentido de sustentar esse imaginário, as próprias políticas públicas de inclusão se constituem sob o princípio da exclusão".

Fica apagado no discurso sobre o encontro no ciberespaço (seja ele de qualquer tipo) "o mercado real, avassalador" (ORLANDI, 2010). O interdito ${ }^{2}$ faz funcionar o discurso possível: o da homogeneização dos serviços e indivíduos, apagando seu caráter político. Porém, no real da "arca ciberespacial" não há nivelamento, autonomia, unidade, conforto, mas, um "salve-se quem puder", pois a porta não está aberta a todos. A arca não poderia absorver todos, já que funciona pela lógica da exclusão, da competitividade.

A naturalização "do sempre possível" do "final feliz", do "encontro alegre" da "arca sob o Monte Ararat" sob determinação das tecnologias é o que permite a movência dos sujeitos.

Lembrando que estamos pensando nas condições verbais do desenvolvimento das discursividades e nas condições sócio históricas determinadas pela lógica capitalista, em suas formas de assujeitamento e modos de individuação, que, na contemporaneidade, apresentam formas inéditas de desigualdades, com novos tipos de coerção (e sofrimento) social. (ORLANDI, 2016, p. 77)

No “dilúvio informacional” (LÉVY, 1999) a questão é de quantidade, que nos leva de volta à Foucault: Édipo não se cegou por culpa mas por excesso de informação. Consoante a Orlandi (2016, p. 77) “à questão da quantidade, acresce-se a do imediatismo, quer seja a do texto, ou a da produção, própria à ideologia pragmática do desenvolvimento".

\section{COOPERAÇÃO, INTELIGÊNCIAS COLETIVAS E OBJETOS DE APRENDIZAGEM: QUAIS SENTIDOS?}

Os sentidos de trabalho cooperativo, interação, compartilhamento têm sido (re)significados no contexto do ciberespaço. Conforme Lemos (2004, p. 11) a cibercultura põe "em sinergia processos de cooperação, de troca e de modificação criativa das obras, dadas as características da tecnologia digital em rede" (LEMOS, 2004, p. 11). Converge o discurso, por isso mesmo, para uma ênfase sobre a co-responsabilidade do outro. Parceria de projetos e união de esforços pelo bem comum são características requeridas do sujeito glocalizado (BAUMANN, 1999), que vive localmente, porém, é determinado pelo global. Dias (2016) afirma que

a colaboratividade e a conectividade são características da mobilidade contemporânea, dos movimentos urbanos contemporâneos, das formas de organização do espaço e das instituições e também da constituição dos sujeitos e dos processos de ressignificação dos sentidos. (DIAS, 2016, p. 37)

\footnotetext{
${ }^{2} \mathrm{O}$ interdito é um impedimento estrutural ao dizer tudo, ao dizer completo. Se existisse uma enunciação ou um enunciado completo que dissesse tudo o que há para dizer, após essa enunciação não haveria mais nada a dizer.
} 
Compreender o funcionamento de "tecnologias e educação" na produção e circulação do conhecimento e na constituição do sujeito do conhecimento contemporâneo é compreender o político, o modo de subjetivação do sujeito numa determinada formação social (ORLANDI, 2001). É perguntar pelo modo como esse sujeito assume uma posição diante das coisas já ditas sobre tecnologias e educação.

A associação entre tecnologias e educação sob o discurso da colaboração é apresentada nos discursos sobre ambientes e objetos de aprendizagem como elemento necessário para a transformação da realidade educacional. Surgem, então, expressões que, ao se apoiarem em expectativas, apresentam esse modo de ser e estar no ciberespaço.

Processo colaborativo; aprendizagem colaborativa; produção colaborativa, atividades instrucionais colaborativas, diálogo colaborativo, equipes técnicas colaborativas, espaço de trabalho virtual colaborativo; sistemas colaborativos; cursos on-line colaborativo, ambiente colaborativo; grupos colaborativos, estratégias colaborativas, dinâmica colaborativa; arranjos colaborativos; práticas colaborativas, saberes colaborativos. (MATEUS et alii, 2012, p. 299)

Mateus et alii (2012) ao realizar estudo tendo como corpus títulos e resumos das teses de doutorado desenvolvidas no Brasil, no período de 2005 a 2010, disponibilizadas pelo Banco de Teses da CAPES (Coordenação de Aperfeiçoamento de Pessoal de Nível Superior) mostra que além da constante retomada das TICs junto ao interdiscurso (aquilo que já fala antes) da colaboração, a unidade lexical 'colaboração' aparece constantemente evocada junto ao discurso da formação de professores. Segundo o autor, o sentido predominante dado ao termo é para designar uma atividade desenvolvida por grupos de pessoas ou, ainda, implica qualquer tipo de cooperação entre partes, o "fazer juntos" para mudar algo. Ele conclui que "nestes trabalhos, há certo efeito de eufemismo, utilizado para evitar e apagar os conflitos. O termo está muito associado a uma questão harmônica, sem conflitos, romantizada" (MATEUS et alii, 2012, p. 304). Fabricação de "um destino humano partilhado" (ORLANDI, 2017, p. 184).

A recorrência do termo 'colaboração' e suas derivações adjetivas nos textos que associam tecnologias e educação trabalham para a construção do envolvimento de indivíduos nos processos de aprendizagem mediada pelo computador em rede. Dessa forma, pensar em produção de objetos de aprendizagem de forma colaborativa, significa romper com a ideia de um saber controlado, dos direitos reservados e da propriedade intelectual.

Nesse acontecimento, no qual estamos inseridos como sujeitos da globalização e das tecnologias de informação e comunicação, investe-se na desestabilização dos lugares do aluno e professor em sua relação com o conhecimento.

A universidade está sendo obrigada a mudar. Já se fala hoje de novos métodos de ensino, a open education. A informação não viaja mais em uma só direção, ela se constrói entre todos os alunos. A informação está na rede e o professor não é mais soberano. A experiência colaborativa 2.0 está cada vez mais presente. O modelo de um professor dogmático deve desaparecer. Um aluno inquieto e curioso tem acesso aos mesmos conteúdos que o professor. A escola será um canalizador de ideias e um orientador [...]. (GUERE, 2010, apud DIAS, 2011, p. 635). 
É consenso nos discursos que trabalham a fórmula tecnologias e educação o argumento da "experiência colaborativa" em oposição ao discurso do saber institucionalizado, "de um professor dogmático". A autoridade e validade do professor "antiquado", "dogmático" são questionadas, sob a política de descentralização da informação e do conhecimento. Articula-se contra o aprendizado individualista e competitivo. Neste ambiente, a colaboratividade é encorajada visando principalmente a descentralização do papel do professor: todos são aprendizes e podem contribuir um com o outro. Articula-se a descentralização nos processos pedagógicos, no sentido de que no ciberespaço o docente não atua sozinho. Ele se encontra em interação com seus pares e com o aluno, tido nesse processo como o principal protagonista (COSTA, 2015).

Orlandi (2017, p. 184).) ao teorizar sobre as formações discursivas da mundialização diz, citando Cohen (2007), que a mundialização não sustenta suas promessas e que, embora os modos de vida, os saberes, as tecnologias se difundam em escala planetária, a grande maioria da humanidade não está em medida de participar da fabricação de "um destino humano partilhado". O que ocorre, é que sob o discurso da globalização tecnológica, tem-se a ilusão de um bem comum a ser partilhado igualmente: o conhecimento, conclui a autora.

Porém, como salienta Orlandi (2017), não se trata de falar em um bem partilhado ou não. "Estamos em uma formação social capitalista e são as relações de trabalho, as relações econômicas e sociais que estão em causa. Se os indivíduos não têm condições materiais de existência favoráveis, não há destino que se cumpra". A autora diz desconfiar da expressão "escala planetária", principalmente se referem à difusão de saberes, tecnologias, modos de vida. Conforme ela, "tudo isso depende de condições concretas e estas como sabemos estão longe de serem "partilhadas" (ORLANDI, 2017, p. 184).

O que ocorre, porém, é que no ciberespaço, ou seja, nos ambientes virtuais, há um imaginário de "difusão de saberes", de "saber (com)partilhado" ligado ao próprio funcionamento das TICs, como disseminadoras do conhecimento. É desse modo que as redes virtuais (ambientes de aprendizagem) se organizam para constituir um sujeito do conhecimento e, ao mesmo tempo, produtor de conhecimento, co-laboradores na produção do conhecimento.

Nos referenciais para a Formação de Professores (MEC) se lê que o princípio da interação e da interatividade (lógica de uma aprendizagem partilhada e coletiva) é fundamental para o processo de comunicação e devem ser garantidos no uso de qualquer meio tecnológico a ser disponibilizado. Porém, em análise de discurso (AD), compreendemos que a interação não é domínio daquele que fala, muito menos da ferramenta; ela se dá nas práticas. No caso que estamos considerando, garantir interatividade não implica estabelecer interação, pois a forma de mediação dependerá da relação entre aquele que diz e aquele que ouve.

Martin-Barbero (1997, p. 256) alerta que a fascinação pela ferramenta por si só "encobre a não-contemporaneidade entre objetos e práticas, entre tecnologias e usos, impedindo-nos assim de compreender os sentidos que sua apropriação adquire historicamente". 


\section{"PRODUÇÃO COLABORATIVA" DO DESIGN DE OBJETOS DE APRENDIZAGEM}

O processo de elaboração de objetos de aprendizagem leva em consideração alguns padrões que deverão ser implementados para que esses objetos possam ser reutilizados em diferentes plataformas e configurações. Granularidade ${ }^{3}$, reusabilidade, interoperabilidade ${ }^{4}$, recuperabilidade são algumas das características técnicas que devem ser consideradas quando se elaboram projetos de e-learning para disponibilização em plataformas ou repositórios de objetos de aprendizagem (COSTA, 2012).

Sendo assim, a construção de objetos de aprendizagem demanda planejamentos técnicos e pedagógicos que estão relacionados à definição do projeto educacional e ao design. Em relação aos aspectos pedagógicos, espera-se que os recursos sejam capazes de garantir a aprendizagem. Por sua vez, os aspectos técnicos requerem protocolos específicos e padrões para entrega de pacotes de conteúdo, garantindo assim a interoperabilidade.

Sob discurso da promoção e compartilhamento do conhecimento, em 2004, a Secretaria de Educação a Distância (SEED/MEC) $)^{5}$, criou a rede social de aprendizagem RIVED (Rede Interativa Virtual de Educação), "produção de conteúdos pedagógicos digitais, na forma de objetos de aprendizagem". A fim de expansão da Rede Interativa Virtual foi oferecido o curso "Como fazer Objetos de Aprendizagem" cujo objetivo era oferecer uma experiência prática e colaborativa para alunos e professores das instituições participantes no processo de design e produção de objetos de aprendizagem (MEC, 2008; grifos nossos).

Considerando que a relação educação e tecnologias, nesse contexto, exige a formação de uma equipe multidisciplinar que envolve não somente profissionais da área de educação, mas, também, e principalmente, especialistas em informática (programadores e web designers) argumenta-se sobre a necessidade de que todos esses profissionais trabalhem colaborativamente em prol do design educacional.

O conceito apreendido pelas expressões design instrucional, design didático, design educacional configura-se como anúncio de novos desafios para a área de educação, funcionando como premissa para a capacitação do professor para atendimento às necessidades impostas pela presença das TICs, que exigiria uma nova "cultura de trabalho multidisciplinar", conforme se lê no livro Objetos de aprendizagem: uma proposta de recurso pedagógico, produzido sob chancela do MEC, em 2007.

A presente publicação é um exemplo ilustrativo das características do processo de produção de objetos de aprendizagem. Esse não é somente mais um livro sobre produção de material didático, pois apresenta relatos de práticas dirigidas aos interesses de educadores e estudiosos do processo ensino/aprendizagem. E, nesse sentido, expressa as

\footnotetext{
${ }^{3} \mathrm{O}$ "tamanho" de um objeto. Um OA de maior granularidade é considerado pequeno, ou em estado "bruto", como a imagem da Monalisa, um texto ou um fragmento de áudio. Um OA de menor granularidade pode ser uma página web inteira, que combina textos, imagens e vídeos, por exemplo (cf. TAROUCO, 2014).

${ }^{4}$ Habilidade de operar através de uma variedade de hardware, sistemas operacionais e browsers, com intercâmbio efetivo entre diferentes sistemas (TAROUCO, 2014).

${ }^{5}$ A extinção da Secretaria de Educação a Distância (SEED/MEC) foi anunciada em janeiro de 2011, pela presidência da república. Ela passou a ser gerida pelas secretarias convencionais, com o mesmo tratamento para as modalidades presenciais e à distância.
} 
reflexões resultantes das experiências das equipes no uso da informática para elaboração de atividades pedagógicas e o estabelecimento de uma nova cultura de trabalho multidisciplinar. (PRATA; NASCIMENTO, 2007, p. 5; grifos nossos)

No mesmo conjunto de textos citado acima, encontramos que "a mudança de paradigma na educação e as políticas de incentivo para formação de uma comunidade de aprendizagem na produção de objetos de aprendizagem" contribuíram e encorajaram uma cultura de desenvolvimento de material educacional com uso de novas tecnologias, para enriquecimento do processo de ensino/aprendizagem. Salienta-se nesse discurso a importância da interatividade e da colaboração, fundamentos dessa "mudança de paradigmas", compreendida como a educação através dos meios, das ferramentas, dos recursos, dos objetos: fundamentos da educação a distância.

Nesse sentido, a aprendizagem é tida como um processo que pode ser previsto, controlado e seus resultados mensurados, em consonância com o design instrucional que valorizando o método faz do ensino/aprendizagem um produto que pode ser produzido em larga escala, por diferentes especialistas (terceirização do conhecimento), numa linha de montagem, com padrões de pacotes de conteúdo. É nesse efeito de sentido que o trabalho colaborativo é significado como atividade e tarefa.

O design instrucional, termo consensualmente aceito, nos textos que relacionam tecnologia e educação, diz respeito ao desenvolvimento sistemático de instrução. Modelos de projetos instrucionais, em geral, especificam um método que, se seguido, facilitará a transferência de conhecimento, habilidades e atitudes para o aprendente. Viabiliza-se, assim, a educação como uma forma de transformar o homem em depósito e reprodutor de conteúdo. O que pressupõe condições industriais de ensino, tendo como base os princípios da divisão do trabalho, linha de montagem e produção em massa.

\section{ENFIM}

Há no discurso educacional, diante do contexto de redefinição do padrão produtivo/econômico/político, a produção de saberes que explicitam o desejo de formação de sujeitos para ajustamento à ordem capitalista neoliberal.

Os processos de desterritorialização ${ }^{6}$ potencializados pelas tecnologias instauraram outras formas de acesso ao saber, a partir da compressão espaço-tempo, criando novas relações entre os sujeitos e a informação. A compressão espaço-tempo criou a possibilidade de acessar a informação em todos os lugares, criando a ilusão de acesso ilimitado ao conhecimento. Conforme Grecco (2016, p. 32) "a imagem que se tem das redes, dos repositórios, dos objetos de aprendizagem, é efeito imaginário de se ter à disposição todo o conhecimento produzido pela humanidade". O que se ignora nesse modo de aprender ou saber sobre as coisas são os modos de constituição desse conhecimento e das relações ideológicas aí investidas.

\footnotetext{
${ }^{6}$ A desterritorialização diz respeito à constituição da escola em outro espaço-tempo, um deslocamento de um lugar físico para o das redes telemáticas. A aposta é que no ciberespaço as fronteiras serão dissolvidas havendo espaço para que todos aprendam, interajam, comuniquem; havendo circulação livre de ideias, informação, produtos, etc. (cf. COSTA, 2015).
} 
Nesses textos, termos como autoaprendizagem, autonomia, interatividade, colaboratividade miram a legitimação do ciberespaço como um lugar privilegiado para renovar a educação tanto em termos metodológicos, quanto na mudança de postura de professores e alunos. É na ideia de flexibilização, desierarquização que se articulam essas mudanças, principalmente em relação às estratégias pedagógicas a serem utilizadas e à relação professor-aluno.

O que é significado como compartilhamento é a disponibilização de um objeto em rede, pelo funcionamento de uma memória metálica, que armazena, acumula e lineariza o interdiscurso, "reduzindo o saber discursivo a um pacote de informações, ideologicamente equivalentes, sem distinguir posições (sem inscrever-se no funcionamento da dissimetria), sem historicizar-se" (ORLANDI, 2016, p. 78).

Aprendizagem colaborativa e design são apresentadas como novas formas de aprender no mundo contemporâneo sob o efeito da realidade do ciberespaço. Nesse contexto, o ato de ensino-aprendizagem é significado como "inteligência coletiva", que resultaria, segundo Lévy $(1999$, p. 28) em uma "mobilização efetiva das competências".

Daí toda a discursividade de que o sujeito da sociedade da informação precisa aprender a trabalhar em equipe, a compartilhar seus conhecimentos, competências e qualidades. Sob ideário neoliberal, o desafio imposto aos indivíduos é de participar cada vez mais de processos de aprendizado colaborativo a fim de gerar capital intelectual compreendido como conhecimento, informação, experiência - que pode ser utilizada para gerar riqueza. Neutralização e naturalização da técnica.

Antes de colocar aqui uma vírgula, faz-se importante refletir sobre três aspectos: não é nada óbvio que a entrada na arca (ciberespaço) signifique oportunidades iguais. Não há mesmo garantia de que as portas estejam igualmente abertas para todos. Não há nenhum fundo sólido sob o oceano das informações.

\section{REFERENCIAS}

BAUMAN, Z. Globalização: as consequências humanas. Rio de Janeiro: Jorge Zahar, 1999. CASTELLS, M. A sociedade em rede. (A era da informação: economia, sociedade e cultura; v.1). Tradução Roneide Venancio Majer. São Paulo: Paz e Terra, 2000; 2007.

COSTA, A. de Fátima. Discursos sobre a educação à distância (EaD): reprodução, confronto, deslocamento de sentidos. Tese. Doutorado em Linguística, Unicamp, IEL, Campinas, 2015.

DIAS, C. A discursividade da rede (de sentidos): a sala de bate-papo HIV. Tese. Doutorado em Linguística. Unicamp, IEL, Campinas, 2004.

. O ensino, a escrita e a leitura. Sobre conectividade e mobilidade. Entremeios [Revista de estudos do discurso], v. 9, jul. 2014. Disponível em http://www.entremeios.inf.br/published/198.pdf. Acesso em 08 de abril de 2016.

; COUTO, O.F. do. As redes sociais na divulgação e formação do sujeito do conhecimento: compartilhamento e produção através da circulação de ideias. Linguagem em (Dis)curso, [S.1.], v. $11, \quad$ n. 3, 631-648, fev. 2012. Disponível em: http://www.portaldeperiodicos.unisul.br/index.php/Linguagem_Discurso/article/view/824/763. Acesso em: 24 ago. 2016.

GRECCO, Cidarley. Redes sociais educacionais: ensino e memória no digital. Revista da ALED (2016). Disponível em: http://raled.comunidadaled.org/index.php/raled/article/view/229/227. Acesso em janeiro de 2017. 
LEMOS, A. Cibercultura, cultura e identidade: em direção a uma "cultura copyleft"? Contemporânea [Revista de Comunicação e Cultura], Salvador, v. 2, n. 2, 9-22, 2004. Disponível em: http://www.portalseer.ufba.br/index.php/contemporaneaposcom/article/viewFile/3416/2486. Acesso em Janeiro de 2017;

LÉVY, P. A inteligência coletiva: por uma antropologia do ciberespaço. São Paulo: Loyola, 2000; 2003.

Cibercultura. Trad. Carlos Irineu da Costa. São Paulo: Ed. 34, 1999.

MACHADO, Glaucio José Couri (Org.). Educação e ciberespaço: estudos, propostas e desafios. Aracaju: Virtus, 2010. p. 255-307.

MARTIN-BARBERO, Jesús. Dos meios as mediações: comunicação, cultura e hegemonia. Rio de Janeiro: Ed. da UFRJ, 1997.

MATEUS, E.; PICONI, L.; EL KADRI, M. Colaboração posta em circulação: etiqueta vazia em práticas discursivas educacionais? Signum: Estudos da Linguagem, v. 15, n. 2, p. 289- 312, 2012. NOGUEIRA, Vanessa dos Santos. Práticas pedagógicas na educação à distância: deslocamentos de memórias e de sentidos. Dissertação. Mestrado em Educação, Programa de PósGraduação em Educação, Santa Maria, RS, 2012;

ORLANDI, E. Eu, Tu, Ele: discurso e real da história. Campinas, SP: Pontes, 2017.

Educação e sociedade: o discurso pedagógico entre o conhecimento e a informação, Revista da ALED, 16 (2), 2016.

Discurso em Análise: sujeito, sentido, ideologia. Campinas, SP : Pontes, 2012.

. A contrapelo: incursão teórica na tecnologia - discurso eletrônico, escola, cidade. Revista

Rua, Campinas, SP, n. 16, vol. 2, nov. 2010.

. Discurso e políticas públicas urbanas: a fabricação do consenso. Campinas: RG, 2010.

Discurso e Texto: formulação e circulação de sentidos. Campinas: Pontes, 2001.

Cidade dos sentidos. Campinas: Pontes, 2004.

Os recursos do futuro: um outro discurso. Multiciência, n. 1, out. 2003.

. Discurso, imaginário social e conhecimento. Em Aberto, Brasília, 14, 61, jan./mar. 1994.

PÊCHEUX, M. Semântica e discurso: uma crítica à afirmação do óbvio. Trad. Bras. $2^{\mathrm{a}}$. ed. Campinas: Editora da Unicamp, 1995;

PRATA, C.L.; NASCIMENTO, A.C.A. de Azevedo (Orgs.). Objetos de aprendizagem: uma proposta de recurso pedagógico. Brasília: MEC, SEED, 2007. Disponível em: http://rived.mec.gov.br/artigos/livro.pdf. Acesso em fevereiro de 2017.

TAROUCO, L.M.R. et. al. (Orgs.). Objetos de Aprendizagem: teoria e prática. Porto Alegre: Evangraf, 2014.

WILEY, D.A. Learning object design and sequencing theory. Tese. Doutorado em Filosofia, Department of Instructional Psychology and Technology, Brigham Young University, 2000. Disponível em: http://opencontent.org/docs/dissertation.pdf. Acesso em: 12 de abril de 2016.

. Connecting learning objects to instructional design theory: A definition, a metaphor, and a taxonomy. In: WILEY, D.A. (Ed.). The Instructional Use of Learning Objects. E-book, 2000. Disponível em: http://reusability.org/read/chapters/wiley.doc. Acesso em: 12 de abril de 2016.

Artigo recebido em: julho de 2018.

Aprovado e revisado em: novembro de 2018.

Publicado em: dezembro de 2018.

Para citar este texto:

COSTA, Aureci de Fatima da. Encontros alegres no ciberespaço: discursos sobre ambientes e objetos de aprendizagem. Entremeios [Revista de Estudos do Discurso, ISSN 2179-3514, online, www.entremeios.inf.br], Seção Estudos, Programa de Pós-Graduação em Ciências da Linguagem (PPGCL), Universidade do Vale do Sapucaí (UNIVÁS), Pouso Alegre (MG), vol. 17, p. 47-59, jul. - dez. 2018.

DOI: http://dx.doi.org/10.20337/ISSN2179-3514revistaENTREMEIOSvol17pagina47a59 